\title{
PRODUÇÃO DE MILHO PIPOCA COM USO DO PÓ DE ROCHA DE BASALTO ASSOCIADO À CAMA DE FRANGO EM LATOSSOLO
}

Thaniel Carlson Writzl ${ }^{1}$, Eduardo Canepelle ${ }^{1}$, Jackson Eduardo Schmitt Stein ${ }^{1}$, Jéssica Taís Kerkhoff ${ }^{1}$, Andersson Daniel Steffler ${ }^{1}$, Darlan Weber da Silva ${ }^{1}$, Marciel Redin $^{2}$

\begin{abstract}
RESUMO - Nas últimas décadas é notável a demanda por alimentos oriundos da agricultura de base ecológica. O objetivo do trabalho foi avaliar a eficiência do pó de rocha de basalto (PRB), de forma pura ou associado com cama de frango (CF) no desenvolvimento de plantas e produtividade de grãos de milho pipoca em um Latossolo. Em condições de campo foram avaliados dois anos consecutivos os seguintes tratamentos: T1 milho pipoca $+40000 \mathrm{~kg} / \mathrm{ha}$ de PRB; T2 - milho pipoca $+1855 \mathrm{~kg} / \mathrm{ha} \mathrm{de} \mathrm{CF}$; T3 - milho pipoca +40000 $\mathrm{kg} / \mathrm{ha}$ de PRB + $1855 \mathrm{~kg} / \mathrm{ha}$ de CF; T4 - milho pipoca + NPK químico; e T5 - milho pipoca (testemunha). Foram avaliados os seguintes parâmetros: altura de plantas, diâmetro de colmos e número de folhas aos 30 , 60 e 90 dias após a semeadura, produtividade de matéria seca da parte aérea e produtividade de grãos. Ainda, avaliou-se nas espigas o número de grãos, comprimento, diâmetro e número de fileiras. O crescimento das plantas e produtividade de grãos nos tratamentos $\mathrm{PRB}+\mathrm{CF}$ e PRB puro apresentaram resultados iguais a fertilização química, mostrando o potencial da fertilização alternativa em solo de alta fertilidade na cultura do milho pipoca.
\end{abstract}

Palavras chave: fertilizante natural, insumos alternativos, rochagem, Zea mays.

\section{PRODUCTION OF POPCORN CROP WITH THE USE OF BASALT ROCK POWDER ASSOCIATED WITH CHICKEN FERTILIZER IN OXISOL}

\begin{abstract}
In the last decades the demand for food from ecologically based agriculture has been remarkable. The objective of this work was to evaluate the efficiency of basalt rock powder (BRP), pure or associated with chicken fertilizer (CF) in plant development and grain yield of popcorn crop in an Oxisol. In field conditions, the following treatments were evaluated for two consecutive years: T1 - popcorn $+40000 \mathrm{~kg} /$ ha of BRP; T2 - popcorn + $1855 \mathrm{~kg} / \mathrm{ha}$ of CF; T3 - popcorn $+40000 \mathrm{~kg} / \mathrm{ha}$ of BRP $+1855 \mathrm{~kg} / \mathrm{ha} \mathrm{of} \mathrm{CF}$; T4 - popcorn + chemical NPK; and T5 - popcorn crop (control). The following parameters were evaluated: plant height, stem diameter and number of leaves at 30, 60 and 90 days after sowing, shoot dry matter yield, grain yield. Also, the grain number, length, diameter and number of rows were evaluated in the spikes. Plant growth and grain yield in the treatments BRP + CF and pure BRP showed similar results to chemical fertilization, showing the potential of alternative fertilization in high fertility soil in the popcorn crop.
\end{abstract}

Keywords: alternative inputs, natural fertilizers, rocking, Zea mays.

\footnotetext{
${ }^{1}$ Acadêmicos do Curso de Bacharelado em Agronomia. Universidade Estadual do Rio Grande do Sul - UERGS. Unidade Três Passos.

${ }^{2}$ Professor da UERGS, Unidade em Três Passos. Endereço para correspondência: Rua Cipriano Barata, nº 211 . Bairro Érico Veríssimo - Três Passos. CEP: 98600-000. Contato: (55) 3522-2895. E-mail: marcielredin@gmail.com
} 


\section{INTRODUÇÃO}

O uso intenso de agroquímicos se tornou fator limitante para produção, porém o uso desenfreado destes, causa o esgotamento e a contaminação de recursos naturais (Gleissman, 2005). Nas últimas décadas, um segmento da pesquisa tem se voltado ao ramo agroecológico, buscando insumos alternativos com potencial de suprir parte ou totalmente a demanda química das fertilizações de culturas de interesse agrícola, e assim, promover a sustentabilidade dos agroecossistemas.

O Brasil é considerado um dos maiores produtores mundiais de alimento, sendo necessário para isso a importação de grandes quantidades de fertilizantes químicos solúveis. Atualmente, o país é um dos maiores importadores de fertilizantes químicos solúveis do mundo, segundo Lopes \& Daher (2008) o Brasil importa $70 \%$ dos fertilizantes que são utilizados na agricultura. Assim, surge recentemente no Brasil a introdução da utilização de rochas moídas na agricultura (rochagem) como alternativa aos fertilizantes químicos importados.

Dentre os pós de rochas, o pó de rocha de basalto (PRB) é aquele que apresenta maior potencial de utilização na agricultura devido sua composição mineralógica diversa e sua ampla distribuição geográfica. O PRB é oriundo da trituração e moagem da rocha basáltica, se destaca como uma importante fonte de nutrientes facilmente intemperizáveis, entre eles o fósforo e potássio (Escosteguy \& Klamt, 1998; Santos et al., 2001). Ainda, o PRB fornece outros macros e micronutrientes, considerados essenciais para o desenvolvimento das plantas. No entanto, o processo de fornecimento de nutrientes do PRB para as culturas, é considerado um processo complexo, pois depende entre outros fatores, da granulometria, tempo de reação além de fatores do próprio solo, como pH e atividade biológica do solo (Santos et al., 2001).

O PRB, entretanto, não possui em sua composição nitrogênio, nutriente essencial para o desenvolvimento das culturas agrícolas principalmente pertencentes à família Poaceae. A mistura de PRB com outros fertilizantes orgânicos ou até mesmo com plantas de cobertura de solo das Fabaceaes são alternativas eficientes para compensar a falta de nitrogênio no PRB. A associação de fertilizantes alternativos, além do fornecimento de nutrientes, estimula a atividade biológica, mantendo o solo mais equilibrado e potencializando a produtividade das culturas. Nesse sentido, Da Silva et al. (2017), destacam que a associação dos pós de rocha com materiais orgânicos que favoreçam a atividade biológica, pode influenciar no processo de alteração dos minerais, contudo é pouco o conhecimento da influência dos materiais sobre a dissolução das rochas moídas com o PRB.

Nesse contexto, ainda são poucos os estudos sobre o uso de PRB na agricultura, utilizado na forma pura e/ou associado com fontes orgânicas de nutrientes, assim há uma necessidade de ampliação das pesquisas nesta temática. Assim, o objetivo através deste trabalho foi avaliar a eficiência do PRB, usado na forma pura ou associado com fertilizante orgânico no desenvolvimento das plantas e produtividade do milho pipoca em Latossolo de alta fertilidade.

\section{MATERIAL E MÉTODOS}

O presente trabalho foi conduzido por dois anos experimentais, correspondentes as safras 2015/2016 e 2016/2017 na região Noroeste do Rio Grande do Sul. O clima da região corresponde, segundo a classificação de Köppen, ao tipo $C f a$, temperado úmido e com verão quente. O solo do local é classificado como um Latossolo Vermelho Distrófico típico (Embrapa, 2013).

Antes da implantação do experimento em cada ano experimental foi realizada amostragem de solo para análise química da fertilidade nas camadas de 0 - 10 e $10-20 \mathrm{~cm}$ de profundidade, a qual indicou alta fertilidade, construída em vários anos de cultivos. $\mathrm{O}$ experimento teve início na safra 2015/2016 em uma área conduzida com sistema de plantio direto consolidado e foi avaliado novamente na safra de 2016/2017 sobre a mesma área e nas mesmas parcelas experimentais do ano anterior. No outono/inverno de 2016, após a colheita do milho do primeiro ano experimental foi implantada a cultura da ervilhaca (Vicia sativa L.). Durante o segundo ano experimental, o experimento foi instalado nas mesmas parcelas do primeiro ano com a mesma metodologia, exceto a aplicação do PRB, que não foi mais aplicado. A semeadura do milho pipoca foi realizada manualmente com espaçamento de $25 \mathrm{~cm}$ entre plantas e $75 \mathrm{~cm}$ entre linhas. O experimento foi implantado em condições naturais de clima e ambiente, sem irrigação. As plantas daninhas foram controladas de forma manual com capinas quinzenais. 
A instalação do experimento nos dois anos experimentais ocorreu em delineamento experimental de blocos casualizados com três repetições. As parcelas eram de $6 \mathrm{~m}^{2}(3 \times 2 \mathrm{~m})$ nas quais foram avaliados os seguintes tratamentos: 1) milho pipoca + PRB;2) milho pipoca $+\mathrm{CF}$; 3) milho pipoca $+\mathrm{PRB}+\mathrm{CF}$; 4) milho pipoca + adubação química - NPK; 5) milho pipoca (testemunha). As doses de cada tratamento, exceto para o PRB, foram estipuladas de acordo com a necessidade do solo apontada pela análise química, e seguindo as orientações do Manual de Adubação e Calagem para os estados do RS e SC (CQFS, 2016). Foram aplicados nos tratamentos 1, 2, 3 e 4, respectivamente: $40000 \mathrm{~kg} / \mathrm{ha}$ de $\mathrm{PRB}$ com aplicação única em superfície no momento da semeadura somente do primeiro ano experimental; $1855 \mathrm{~kg} / \mathrm{ha}$ de CF com aplicação dividida sendo $1 / 2$ no momento da semeadura $\mathrm{e}^{1 / 2} \mathrm{em}$ cobertura; $40000 \mathrm{~kg} / \mathrm{ha}$ de PRB e mais $927 \mathrm{~kg} /$ ha de CF no momento da semeadura, e posteriormente mais $927 \mathrm{~kg} / \mathrm{ha}$ de CF em cobertura; $100 \mathrm{~kg} / \mathrm{ha}$ de sulfato de amônio, $183 \mathrm{~kg} / \mathrm{ha}$ de superfosfato triplo e $86 \mathrm{~kg} /$ ha de cloreto de potássio aplicados no momento da semeadura $+45 \mathrm{~kg} / \mathrm{ha}$ de ureia em cobertura (NPK). A dose do PRB foi definida de forma relativa, pelo fato de não existirem trabalhos conclusivos que indiquem doses de PRB, incluindo a CQFS (2016), bem como pela viabilidade técnico-logística de aplicação e financeira. O PRB aplicado a lanço em dose única na superfície do solo apresentava as seguintes propriedades químicas: $\mathrm{Ca}=12,7 \mathrm{mmol}_{\mathrm{c}} \mathrm{dm}^{-3} ; \mathrm{Mg}=2,4 \mathrm{mmol}_{\mathrm{c}} \mathrm{dm}^{-}$ 3; $\mathrm{Al} \mathrm{e} \mathrm{H}+\mathrm{Al}=0,0 \mathrm{mmol}_{\mathrm{c}} \mathrm{dm}^{-3}$; saturação por bases $=96 \% ; \mathrm{S}=7 \mathrm{mg} \mathrm{dm}^{-3} ; \mathrm{P}\left(\right.$ Mehlich-1) $=349 \mathrm{mg} \mathrm{dm}^{-3}$ e $\mathrm{K}=72 \mathrm{mg} \mathrm{dm}^{-3}$.

Com o propósito de avaliar o efeito dos diferentes tratamentos, no crescimento das plantas de milho pipoca, as mesmas foram monitoradas mensalmente, com avaliações sendo realizada aos 30,60 e 90 dias após a semeadura. Para a realização das avaliações morfológicas, após a emergência das plantas, foram selecionadas quatro plantas nas duas linhas centrais de cada parcela, sendo nestas plantas avaliados parâmetros de altura, diâmetro de colmo e número de folhas. No pleno florescimento, foram coletadas outras quatro plantas e secas em estufa a $65^{\circ} \mathrm{C}$ para determinação da produção de matéria seca (MS). A colheita foi realizada no estádio de maturação fisiológica das plantas. Foram colhidas as quatro plantas utilizadas nas avaliações fenológicas e nas espigas, após secas foram avaliados o comprimento de espigas, diâmetro espigas, número de fileiras de grãos e o peso de mil sementes (PMS). A avaliação da produtividade de grãos foi realizada nas mesmas espigas das quatro plantas avaliadas inicialmente, as quais foram debulhadas e pesadas. As avaliações de produtividade de grãos e PMS foram realizadas com a umidade corrigida para $13 \%$. Os dados obtidos foram submetidos a análise de variância (ANOVA), seguido pelo teste de Tukey a $5 \%$ de probabilidade de erro.

\section{RESULTADOS E DISCUSSÃO}

A análise dos dados mostrou diferença significativa entre os anos experimentais, tratamentos e variáveis avaliadas (Tabela 1).

No segundo ano experimental, observou-se maior crescimento de plantas, mesmo tendo um retardo inicial aos 30 dias. Esse resultado, provavelmente esteja relacionado com chuvas melhores distribuídas durante o ciclo da cultura, menor variação de temperatura (Figura 1A) e maior incidência de radiação solar (Figura 1B). No primeiro ano experimental, ocorreu um período de altas temperaturas e baixo índice pluviométrico no mês de janeiro, quando o milho pipoca estava no estádio reprodutivo de embonecamento e enchimento de grãos (Figura 1A).

O cultivo da ervilhaca no inverno também contribuiu para o incremento de nutrientes, em especial o nitrogênio para o milho pipoca cultivado em sucessão no segundo ano experimental. Neste sentido, Aita et al. (2001) verificaram que milho semeado sobre os resíduos de ervilhaca, apresentou produtividade de grãos igual a do tratamento químico com NPK. Ainda, de acordo com Aita et al. (2001) isto ocorre devido a grande quantidade de nitrogênio presente na parte área da ervilhaca, sendo que este nitrogênio estará disponível depois no resíduo da cultura para ser utilizado pelas plantas semeadas em sucessão.

Segundo Da Silva et al. (2017), devido a liberação gradativa e lenta de nutrientes do PRB, são promovidas alterações nas propriedades químicas do solo. No presente estudo também foram observadas alterações nas propriedades químicas do solo no segundo ano experimental (Tabela 2). O Ca foi principal nutriente que sofreu alterações, pois nos tratamentos de PRB puro e associado a CF verificou-se aumento de $98 \%$ e $117 \%$ deste nutriente na camada de $0-20 \mathrm{~cm}$ 
Tabela 1 - Análise da variância entre as variáveis avaliadas em relação aos dois anos experimentais e tratamentos pelo teste de Tukey a $5 \%$

\begin{tabular}{ll}
\hline \multicolumn{1}{c}{ Parâmetros } & Valor P \\
\hline Ano x tratamento x matéria seca da parte aérea & 0,0001 \\
Ano x tratamento x produtividade de grãos & 0,0454 \\
Ano x tratamento x peso de mil sementes & 0,0262 \\
Ano x tratamento x comprimento de espiga & 0,0010 \\
Ano x tratamento x diâmetro de espiga & 0,0202 \\
Ano x tratamento x número de fileiras & 0,0117 \\
Ano x tratamento x altura 30 dias & 0,0021 \\
Ano x tratamento x diâmetro de colmo 30 dias & 0,0236 \\
Ano x tratamento x número de folhas 30 dias & 0,0003 \\
Ano x tratamento x altura 60 dias & 0,0106 \\
Ano x tratamento x diâmetro de colmo 60 dias & 0,0252 \\
Ano x tratamento x número de folhas 60 dias & 0,0018 \\
Ano x tratamento x altura 90 dias & 0,0349 \\
Ano x tratamento x diâmetro de colmo 90 dias & 0,0001 \\
Ano x tratamento x número de folhas 90 dias & 0,0410 \\
\hline
\end{tabular}
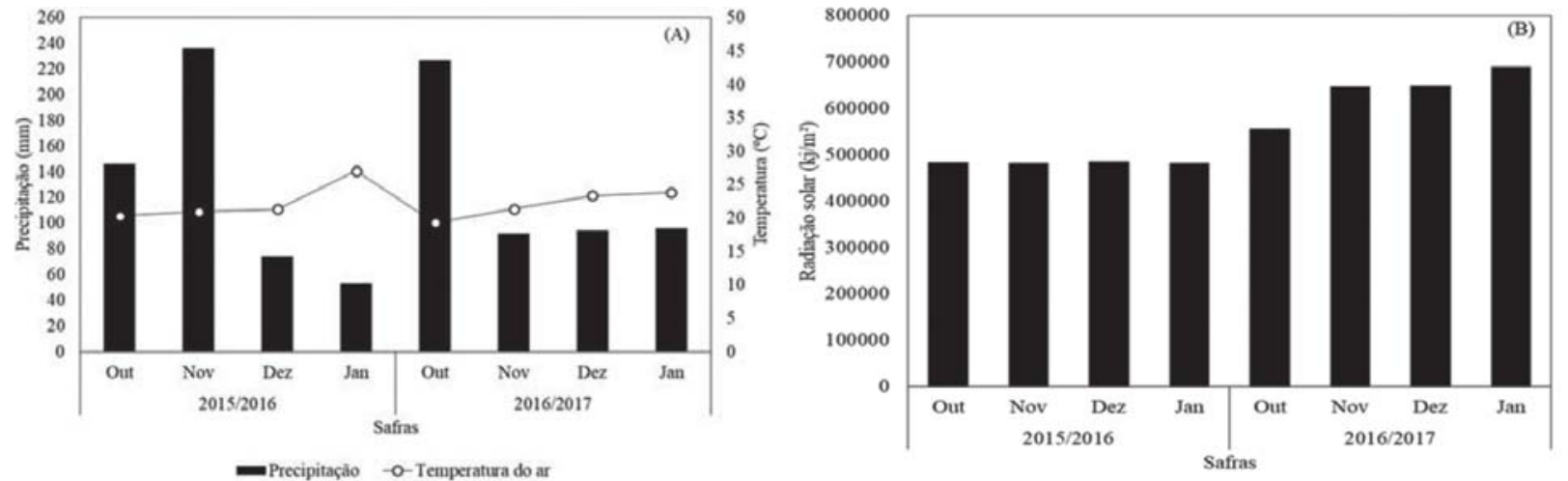

Figura 1 - Precipitações pluviométricas, média da temperatura do ar (A) e radiação solar total (B) nos dois anos experimentais.

Tabela 2 - Propriedades químicas do solo no início dos dois anos experimentais

\begin{tabular}{|c|c|c|c|c|c|c|c|c|c|c|}
\hline Anos & Tratamentos & $\begin{array}{c}\text { Prof. } \\
\text { Cm }\end{array}$ & $\begin{array}{l}\mathrm{pH}^{\mathrm{a}} \\
\mathrm{H}_{2} \mathrm{O}\end{array}$ & $\begin{array}{l}\mathrm{V} \\
\%\end{array}$ & $\begin{array}{c}\text { MOS } \\
\%\end{array}$ & $\begin{array}{c}\mathrm{P} \\
\mathrm{mg} \mathrm{kg}^{-1}\end{array}$ & $\begin{array}{c}\mathrm{K} \\
\mathrm{mg} \mathrm{kg}^{-1}\end{array}$ & $\begin{array}{c}\mathrm{H}+\mathrm{Al} \\
\mathrm{mmol}_{\mathrm{c}} \mathrm{dm}^{-3}\end{array}$ & $\begin{array}{c}\mathrm{Ca} \\
\mathrm{mmol}_{\mathrm{c}} \mathrm{dm}^{-3}\end{array}$ & $\begin{array}{c}\mathrm{Mg} \\
\mathrm{mmol}_{\mathrm{c}} \mathrm{dm}^{-3}\end{array}$ \\
\hline \multirow{2}{*}{2015} & & $0-10$ & 5,6 & 64,5 & 3,2 & 10,2 & 156,4 & 2,8 & 3,1 & 3,5 \\
\hline & & $10-20$ & 5,2 & 41,3 & 2,4 & 8,7 & 80,3 & 2,9 & 2,6 & 2,7 \\
\hline \multirow[t]{10}{*}{2016} & \multirow[t]{2}{*}{ PRB } & $0-10$ & 5,3 & 69,2 & 3,5 & 11,8 & 162,2 & 2,2 & 6,1 & 4,1 \\
\hline & & $10-20$ & 5,7 & 44,3 & 2,8 & 8,9 & 86,1 & 2,0 & 5,2 & 3,6 \\
\hline & \multirow[t]{2}{*}{$\mathrm{CF}$} & $0-10$ & 4,9 & 66,5 & 3,0 & 13,5 & 171,3 & 3,1 & 4,2 & 3,4 \\
\hline & & $10-20$ & 5,4 & 42,7 & 2,7 & 9,1 & 75,1 & 3,5 & 3,6 & 3,0 \\
\hline & \multirow[t]{2}{*}{$\mathrm{PRB}+\mathrm{CF}$} & $0-10$ & 5,0 & 75,2 & 3,6 & 17,4 & 195,2 & 3,0 & 6,9 & 4,3 \\
\hline & & $10-20$ & 5,9 & 48,9 & 2,1 & 9,4 & 93,4 & 3,4 & 5,5 & 2,9 \\
\hline & \multirow[t]{2}{*}{ Químico } & $0-10$ & 5,5 & 55,4 & 3,3 & 14,3 & 145,2 & 3,2 & 2,0 & 2,7 \\
\hline & & $10-20$ & 5,1 & 39,5 & 2,2 & 9,2 & 76,2 & 3,5 & 2,2 & 2,2 \\
\hline & \multirow[t]{2}{*}{ Testemunha } & $0-10$ & 5,8 & 53,8 & 3,4 & 9,5 & 145,7 & 2,5 & 2,9 & 3,4 \\
\hline & & $10-20$ & 4,7 & 37,1 & 2,5 & 8,0 & 69,9 & 3,4 & 2,1 & 2,0 \\
\hline
\end{tabular}

apH: Potencial de hidrogênio; V: Saturação por bases; MOS: Matéria orgânica do solo; P: Fósforo; K: Potássio; H+Al: Acidez potencial; Ca: Cálcio; Mg: Magnésio. 
respectivamente. Já no tratamento com a fertilização química houve uma diminuição de $25 \%$ nas quantidades de Ca presente no solo.

No fornecimento de $\mathrm{Mg}$, foi observado um aumento de $25 \%$ no tratamento de PRB e $15 \%$ no tratamento de PRB associado a CF, enquanto na fertilização química houve uma diminuição de $21 \%$. Em relação ao K, os tratamentos com PRB tanto puro, quanto associado a $\mathrm{CF}$, apresentaram um aumento de $5 \%$ e $21 \%$, respectivamente. Segundo Santos et al. (2001), os fertilizantes alternativos, como o PRB, fornecem uma grande quantidade de benefícios aos solos, tem maior efeito residual, tornando assim, uma alternativa promissora em relação aos fertilizantes químicos altamente solúveis, que precisam ser dispostos as plantas a cada cultura, devido a sua alta volatilização, lixiviação e/ou a percolação.

O tratamento testemunha apresentou os menores valores em todos os parâmetros fenológicos avaliados, exceto para o diâmetro de colmo aos 30,60 e 90 dias do segundo ano experimental, no qual a testemunha se igualou aos demais fertilizantes (Tabela 3 ).

Na avaliação de 30 dias no ano de 2016, não houve diferença para nenhum fertilizante nos parâmetros de altura, diâmetro de colmos e número de folhas. Esse resultado, pode estar associado a química do solo, a qual apresentava alta fertilidade (Tabela 2). Porém, nas avaliações de 60 e 90 dias diferenças significativas começaram a ser notadas, onde o tratamento de PRB + CF superou a fertilização química, uma vez que nos fertilizantes orgânicos, os nutrientes estão na forma orgânica e na maioria indisponíveis para as plantas. Segundo Da Silva et al. (2017), somente após uma ação microbiológica no material orgânico que os nutrientes estarão dispostos na forma inorgânica na solução do solo para a absorção das raízes. O tratamento com PRB no ano 2016 apresentou a menor altura de plantas no período inicial de 30 dias, assim, a ausência do nitrogênio na composição da rocha basáltica pode ter sido a causa desse baixo desenvolvimento inicial das plantas.

A associação de PRB misturado com CF promoveu o melhor desenvolvimento das plantas, ou seja, altura, diâmetro de colmo e número de folhas por planta, igualando-se a fertilização química. Assim, a associação de PRB $+\mathrm{CF}$, mesmo em solo com alta fertilidade, pode ser entendido como uma boa alternativa para substituir a fertilização química. Todavia, nas avaliações realizadas nas espigas, a mistura de PRB com CF se igualou e superou a fertilização química na produtividade de grãos e número de fileiras, respectivamente. Porém, o PMS foi inferior nos dois anos avaliados. Tais resultados,

Tabela 3 - Altura, diâmetro (Ø) de colmo e número de folhas aos 30,60 e 90 dias após a semeadura: pó de rocha de basalto (PRB), cama de frango $(\mathrm{CF})$, pó de rocha de basalto + cama de frango (PRB + CF), químico - NK e testemunha, nos dois anos experimentais

\begin{tabular}{|c|c|c|c|c|c|c|c|}
\hline \multirow{2}{*}{ Tratamentos } & \multirow{2}{*}{ Parâmetros } & \multicolumn{3}{|c|}{2015} & \multicolumn{3}{|c|}{2016} \\
\hline & & 30 dias & 60 dias & 90 dias & 30 dias & 60 dias & 90 dias \\
\hline \multirow[t]{3}{*}{ PRB } & Altura $(\mathrm{cm})$ & $52,7 \mathrm{Abc} *$ & $76,3 \mathrm{Ba}$ & $213,1 \mathrm{Ba}$ & $37,4 \mathrm{Ba}$ & $110,9 \mathrm{Ab}$ & $244,3 \mathrm{Aab}$ \\
\hline & $\varnothing$ de colmo $(\mathrm{cm})$ & $0,9 \mathrm{Bab}$ & 1,2 Bab & $1,6 \mathrm{Ba}$ & $1,8 \mathrm{Aa}$ & 2,3 Aa & $1,9 \mathrm{Ab}$ \\
\hline & $N^{o}$ folhas & $6,9 \mathrm{Aa}$ & $9,9 \mathrm{Bb}$ & $13,1 \mathrm{Bab}$ & $7,8 \mathrm{Aa}$ & $11,0 \mathrm{Aa}$ & $14,5 \mathrm{Abc}$ \\
\hline \multirow[t]{3}{*}{$\mathrm{CF}$} & Altura $(\mathrm{cm})$ & $61,5 \mathrm{Aab}$ & $79,0 \mathrm{Ba}$ & $231,8 \mathrm{Ba}$ & $39,8 \mathrm{Ba}$ & $111,4 \mathrm{Ab}$ & $256,5 \mathrm{Aa}$ \\
\hline & $\varnothing$ de colmo $(\mathrm{cm})$ & $1,0 \mathrm{Bab}$ & 1,2 Bab & 1,3 Bab & $1,9 \mathrm{Aa}$ & $2,6 \mathrm{Aa}$ & $2,1 \mathrm{Aab}$ \\
\hline & $\mathrm{N}^{\mathrm{o}}$ folhas & $6,7 \mathrm{Aa}$ & $10,7 \mathrm{Bab}$ & $13,3 \mathrm{Ba}$ & $7,7 \mathrm{Aa}$ & $12,4 \mathrm{Aa}$ & $14,4 \mathrm{Abc}$ \\
\hline \multirow[t]{3}{*}{$\mathrm{PRB}+\mathrm{CF}$} & Altura (cm) & $69,0 \mathrm{Aa}$ & $83,6 \mathrm{Ba}$ & $213,1 \mathrm{Ba}$ & $37,4 \mathrm{Ba}$ & $130,3 \mathrm{Aa}$ & $266,0 \mathrm{Aa}$ \\
\hline & $\varnothing$ de colmo $(\mathrm{cm})$ & $1,3 \mathrm{Ba}$ & $1,5 \mathrm{Ba}$ & $1,6 \mathrm{Ba}$ & $1,8 \mathrm{Aa}$ & $2,6 \mathrm{Aa}$ & $2,3 \mathrm{Aa}$ \\
\hline & $\mathrm{N}^{\circ}$ folhas & $7,8 \mathrm{Aa}$ & $11,6 \mathrm{Ba}$ & $13,8 \mathrm{Ba}$ & $7,8 \mathrm{Aa}$ & $12,3 \mathrm{Aa}$ & $15,7 \mathrm{Aa}$ \\
\hline \multirow{3}{*}{ Químico } & Altura $(\mathrm{cm})$ & $58,9 \mathrm{Aab}$ & $77,4 \mathrm{Ba}$ & $206,7 \mathrm{Bab}$ & $40,6 \mathrm{Ba}$ & $115,1 \mathrm{Ab}$ & $256,2 \mathrm{Aa}$ \\
\hline & $\varnothing$ de colmo $(\mathrm{cm})$ & $1,2 \mathrm{Ba}$ & 1,3 $\mathrm{Bab}$ & $1,4 \mathrm{Bab}$ & $1,9 \mathrm{Aa}$ & $2,5 \mathrm{Aa}$ & $2,1 \mathrm{Aab}$ \\
\hline & $\mathrm{N}^{\mathrm{o}}$ folhas & 7,3 Aa & $9,9 \mathrm{Bb}$ & $13,3 \mathrm{Ba}$ & 7,2 Aa & $12,0 \mathrm{Aa}$ & $15,3 \mathrm{Aab}$ \\
\hline \multirow{3}{*}{ Testemunha } & Altura $(\mathrm{cm})$ & $46,5 \mathrm{Ac}$ & $73,2 \mathrm{Ba}$ & $177,2 \mathrm{Bb}$ & $33,7 \mathrm{Ba}$ & $108,3 \mathrm{Ab}$ & $221,8 \mathrm{Ab}$ \\
\hline & $\varnothing$ de colmo $(\mathrm{cm})$ & $0,7 \mathrm{Bb}$ & $1,0 \mathrm{Bb}$ & $1,2 \mathrm{Bb}$ & 1,6 Aa & $2,4 \mathrm{Aa}$ & $2,3 \mathrm{Aa}$ \\
\hline & $\mathrm{N}^{\circ}$ folhas & $5,0 \mathrm{Bb}$ & $9,4 \mathrm{Bb}$ & $12,2 \mathrm{Bb}$ & $7,8 \mathrm{Aa}$ & $12,3 \mathrm{Aa}$ & $13,5 \mathrm{Ac}$ \\
\hline
\end{tabular}

*Letras minúsculas e maiúsculas iguais, nas colunas e linhas, respectivamente, para cada parâmetro e datas nos anos experimentais não diferem estatisticamente pelo teste de Tukey $5 \%$. 
devem-se a rápida disponibilização de nutrientes da $\mathrm{CF}$, especialmente o nitrogênio, assim associada ao $\mathrm{PRB}$, que possui liberação mais lenta e gradativa, favorece o fornecimento ideal de nutrientes em todo o ciclo da cultura, ao contrário, de acordo com Plewka et al. (2009), da fertilização química, que ao ser depositada no solo, fica totalmente disponível para a absorção pelas raízes ou perdida por lixiviação.

A produção de MS da parte aérea das plantas no ano de 2015 foi menor, porém destacando-se os tratamentos com PRB, tanto puro, quanto associado com a CF e o tratamento químico, com uma produção de 7238,5388 e $7475 \mathrm{~kg} / \mathrm{ha}$, respectivamente (Figura $2 \mathrm{~A}$ ).

No ano de 2016, os tratamentos de PRB puro, e $\mathrm{PRB}+\mathrm{CF}$, diferiram entre si com produções de 9682 e $8886 \mathrm{~kg} / \mathrm{ha}$, respectivamente, tal diferença pode ser explicada pela deficiência de $\mathrm{N}$ na composição mineralógica da rocha. Porém, estes dois tratamentos não diferiram da fertilização química, a qual apresentou uma produção de $9159 \mathrm{~kg} / \mathrm{ha}$. O tratamento com o PRB, em comparação a fertilização química, apresentou igual desenvolvimento morfológico e produtividade de MS (Tabela 3; Figura 2A). Resultados similares de produção de MS de plantas e produtividade de grãos foram obtidos por Silverol \& Filho (2007), na utilização de diversos pós de rochas na cultura do milho.

Nas avaliações de produtividade de grãos (Figura 2 B) e espigas (Tabela 4), a produtividade de grãos foi superior para o tratamento com PRB + CF no ano de 2016.

Em relação ao ano de 2015 não houve diferenças significativas entre os tratamentos para o comprimento, diâmetro e número de fileiras por espiga, exceto para os tratamentos com CF e fertilização química, que foram inferiores igualando-se a testemunha, com 12,2, 11,8 e 10,1 fileiras por espiga, respectivamente. Já no ano de 2016, o tratamento de PRB puro, e químico apresentaram resultados superiores no PMS em relação aos demais tratamentos. Tais resultados foram semelhantes aos obtidos por Knapik et al. (2005) que realizaram testes com PRB na cultura da soja com doses de 0,5 e $2 \mathrm{~kg} / \mathrm{m}^{2}$, apresentando resultados superiores no PMS quando aplicado em maior dose, sendo que o mesmo constatou que a fertilização química com NPK solúvel foi inferior neste parâmetro avaliado.

A produção de grãos no tratamento $\mathrm{PRB}+\mathrm{CF}$, em 2015 foi inferior da safra 2016, no entanto, a produção grãos obtida na safra de 2015 foi igual dos outros tratamentos para aquele ano de avaliação (Figura 2B). Para os demais tratamentos não houve diferença na produção de grãos entre os anos 2015 e 2016. Na safra de 2015, a fertilização realizada com PRB puro e PRB $+\mathrm{CF}$, proporcionaram uma produtividade de grãos de 3499 e $3253 \mathrm{~kg} / \mathrm{ha}$, respectivamente, igualando-se a fertilização química com produtividade de $3519 \mathrm{~kg} / \mathrm{ha}$. Esses resultados se repetiram no ano de 2016, onde foi obtida uma produtividade de 3779 e $3800 \mathrm{~kg} / \mathrm{ha}$ para os tratamentos de $\mathrm{PRB}$ puro e $\mathrm{PRB}+\mathrm{CF}$, respectivamente e $3854 \mathrm{~kg} /$ ha no tratamento com fertilização química NPK.

Os resultados obtidos neste estudo corroboram com de Hanisch et al. (2011), os quais não evidenciaram diferença significativa para altura de plantas, massa de grãos e número de grãos por espiga, todavia, a fertilização com PRB promoveu aumento da produtividade de grãos de milho. Tais resultados podem
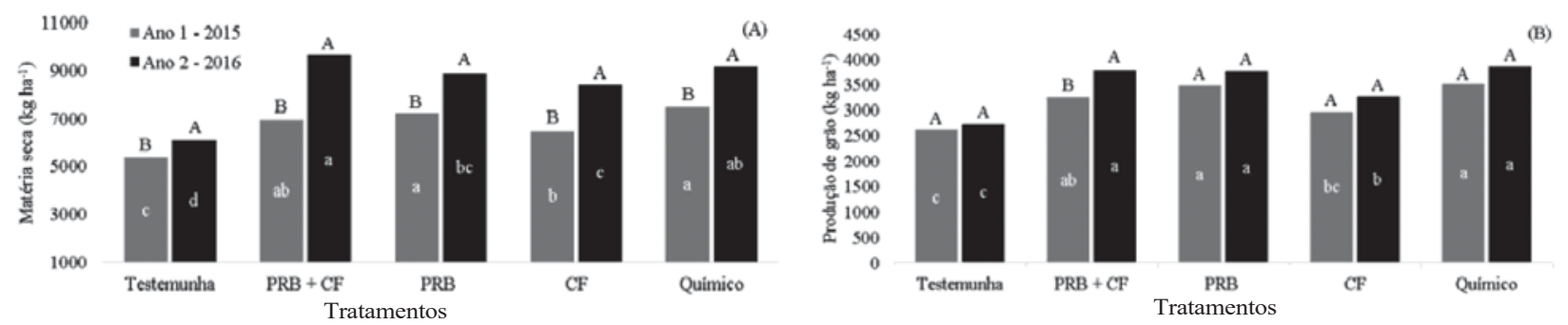

Figura 2 - Produção de matéria seca da parte aérea (A) e produção de grãos de milho pipoca (B). Pó de rocha de basalto + cama de frango (PRB + CF); pó de rocha de basalto (PRB) e cama de frango (CF). Letras maiúsculas iguais não apresentam diferença significativa entre as médias dos anos, assim como letras minúsculas iguais, não representam diferença significativa entre as médias dos tratamentos, pelo teste de Tukey a $5 \%$. 
Tabela 4 - Comprimento, diâmetro (Ø), número de fileiras por espigas e peso de mil sementes (PMS) de milho pipoca. Pó de rocha de basalto (PRB), cama de frango (CF), pó de rocha de basalto + cama de frango $(\mathrm{PRB}+\mathrm{CF})$, químico e testemunha, nos dois anos experimentais

\begin{tabular}{|c|c|c|c|}
\hline Tratamentos & Parâmetros & 2015 & 2016 \\
\hline PRB & $\begin{array}{l}\text { Comprimento espigas }(\mathrm{cm}) \\
\varnothing \text { espigas }(\mathrm{cm}) \\
\mathrm{N}^{\mathrm{o}} \text { fileiras } \\
\text { PMS }(\mathrm{g})\end{array}$ & $\begin{array}{r}13,3 \mathrm{Aa}^{*} \\
3,5 \mathrm{Aa} \\
12,8 \mathrm{Aab} \\
176,0 \mathrm{Ba}\end{array}$ & $\begin{array}{l}14,1 \mathrm{Abc} \\
3,6 \mathrm{Aab} \\
13,0 \mathrm{Ab} \\
199,3 \mathrm{Aa}\end{array}$ \\
\hline $\mathrm{CF}$ & $\begin{array}{l}\text { Comprimento espigas }(\mathrm{cm}) \\
\varnothing \text { espigas }(\mathrm{cm}) \\
\mathrm{N}^{\mathrm{o}} \text { fileiras } \\
\text { PMS }(\mathrm{g})\end{array}$ & $\begin{array}{c}12,9 \mathrm{Ba} \\
3,3 \mathrm{Aa} \\
12,2 \mathrm{Bb} \\
143,7 \mathrm{Ab}\end{array}$ & $\begin{array}{c}15,2 \mathrm{Aab} \\
3,5 \mathrm{Aab} \\
13,4 \mathrm{Aab} \\
150,0 \mathrm{Ac}\end{array}$ \\
\hline $\mathrm{PRB}+\mathrm{CF}$ & $\begin{array}{l}\text { Comprimento espigas }(\mathrm{cm}) \\
\varnothing \text { espigas }(\mathrm{cm}) \\
\mathrm{N}^{\mathrm{o}} \text { fileiras } \\
\mathrm{PMS}(\mathrm{g})\end{array}$ & $\begin{array}{c}14,3 \mathrm{Ba} \\
3,4 \mathrm{Ba} \\
13,5 \mathrm{Aa} \\
148,3 \mathrm{Bb}\end{array}$ & $\begin{array}{c}17,1 \mathrm{Aa} \\
3,8 \mathrm{Aa} \\
14,2 \mathrm{Aa} \\
172,0 \mathrm{Ab}\end{array}$ \\
\hline Químico & $\begin{array}{l}\text { Comprimento espigas }(\mathrm{cm}) \\
\varnothing \text { espigas }(\mathrm{cm}) \\
\mathrm{N}^{\mathrm{o}} \text { fileiras } \\
\text { PMS }(\mathrm{g})\end{array}$ & $\begin{array}{c}12,7 \mathrm{Bab} \\
3,3 \mathrm{Aa} \\
11,8 \mathrm{Bb} \\
169,7 \mathrm{Aa}\end{array}$ & $\begin{array}{l}14,1 \mathrm{Abc} \\
3,5 \mathrm{Aab} \\
12,6 \mathrm{Abc} \\
181,3 \mathrm{Aab}\end{array}$ \\
\hline Testemunha & $\begin{array}{l}\text { Comprimento espigas }(\mathrm{cm}) \\
\varnothing \text { espigas }(\mathrm{cm}) \\
\mathrm{N}^{\circ} \text { fileiras } \\
\text { PMS }(\mathrm{g})\end{array}$ & $\begin{array}{c}10,9 \mathrm{Bb} \\
2,9 \mathrm{Bb} \\
10,1 \mathrm{Bc} \\
122,3 \mathrm{Bc}\end{array}$ & $\begin{array}{c}12,5 \mathrm{Ac} \\
3,3 \mathrm{Ab} \\
11,8 \mathrm{Ac} \\
136,0 \mathrm{Ac}\end{array}$ \\
\hline
\end{tabular}

* Letras minúsculas e maiúsculas iguais, nas colunas e linhas, respectivamente, não diferem estatisticamente pelo teste de Tukey a 5\%.

ser explicados pela alta fertilidade da área de estudo, uma vez que a mesma já apresentava níveis elevados de nutrientes. Ferreira et al. (2009), destacam que associação de esterco de origem animal com PRB promoveu um pequeno incremento na produtividade de grãos na cultura do feijão em doses de $10 \mathrm{Mg} / \mathrm{ha}$. Ainda, nesse sentido, Da Silva et al. (2017), relata que este incremento na produtividade pode estar associado a solubilização da rocha promovida pelos microrganismos presentes no material orgânico (esterco), os quais liberam os nutrientes presentes na mistura (PRB + material orgânico) gradativamente para a solução do solo.

Os resultados obtidos no presente estudo mostram que a introdução dos insumos alternativos, em especial o PRB associado com CF, mesmo em solo de alta fertilidade, apresenta grandes vantagens, principalmente quando comparada a produtividade de grãos do milho pipoca com a fertilização química. Segundo Santos et al. (2001), o PRB devido ao seu potencial residual, permanecerá no solo por maior período de tempo para as culturas sucessoras, diminuindo, assim a aplicação de fertilizantes, mão de obra e poluição do ambiente.
Ainda, é uma prática ambientalmente correta, que apresenta mínimos impactos ao meio ambiente, além de favorecer equilíbrio químico e biológico do solo. Aliado a isso, com a integração da prática de rochagem, é possível haver a diminuição da importação de fertilizantes, os quais são finitos. Assim, a utilização de insumos alternativos, como o PRB, seria uma ótima opção para as necessidades do atual modelo agrícola, uma vez que estes insumos apresentam potencial produtivo similar aos químicos, além do menor impacto ambiental.

\section{CONCLUSÕES}

O uso de PRB puro ou misturado com CF, apresenta ação equivalente no desenvolvimento das plantas e produtividade de grãos de milho pipoca em comparação com a fertilização química em Latossolo de alta fertilidade.

É necessário a realização de novas pesquisas voltadas a esta temática, porém em solos de baixa e média fertilidade, além experimentos relacionados com doses de PRB. 


\section{LITERATURACITADA}

AITA, C.; BASSO, C.J.; CERETTA, C.A. et al. Plantas de cobertura de solo como fonte de nitrogênio ao milho. Revista Brasileira de Ciência do Solo, v.25, n.1, p.157-165, 2001.

CQFS/RS-SC. Comissão de Química e Fertilidade do Solo RS-SC. Manual de adubação e calagem para os estados do Rio Grande do Sul e Santa Catarina. Porto Alegre: Sociedade Brasileira de Ciência do Solo, 2016.324p.

DA SILVA, V.A; DA SILVA, L.E.S.F.; DA SILVA, A.J.N. et al. Solubility curve of rock powder inoculated with microorganisms in the production of biofertilizers. Agriculture and Natural Resources, v.51, p.142-147, 2017.

EMBRAPA - Empresa Brasileira de Pesquisa Agropecuária. Centro Nacional de Pesquisa de Solos. Sistema Brasileiro de Classificação de solos. Embrapa Produção de Informação, 3.ed., 2013. 353p.

ESCOSTEGUY, P.A.V.; KLAMT, E. Basalto moído como fonte de nutrientes. Revista Brasileira de Ciência do Solo, v.22, n.1, p.11-20, 1998.

FALEIRO, F.G.; NETO, A.L.F. Agronegócio e recursos naturais no Cerrado: desafios para uma coexistência harmônica. IN: LOPES, A.S. \& DAHER, E. Desafios e estratégias para o equilíbrio entre sociedade, agronegócio e recursos naturais. $1^{\mathrm{a}} \mathrm{ed}$. Planaltina, DF: Embrapa Cerrados, 2008. p.173-209.

FERREIRA, E.R.N.C.; ALMEIDA, J.A.; MAFRA, A.L. Powder basalt, development and nutrition of common bean (Phaseolus vulgaris) and chemical properties of an andy loam Humic Cambisol. Revista de Ciências Agroveterinárias, v.8, n.2, p.111-121, 2009.
GLEISSMAN, S.R. Agroecologia: processos ecológicos em agricultura sustentável. Editora da UFRGS, 2005. 653p.

HANISCH, A.L.; FONSECA, J.A.; VOGT, G.A. et al. Desempenho da cultura do milho em diferentes doses de pó de basalto, com e sem fertilização In: $8^{\circ}$ Reunião técnica catarinense de Milho e Feijão. Anais... Chapecó-Santa Catarina: Epagri, 2011.4p. Seção Milho, 5.9. CD-ROM.

KNAPIK, B.; KNAPIK, J.G.; SILVA, F.J.P. Utilização de pó de basalto como substituto a adubação química no plantio de soja. In: $3^{\circ}$ Congresso Brasileiro de Agroecologia, $3^{\circ}$ Seminário Estadual de Agroecologia. 2005, Florianópolis. Anais... Florianópolis-Santa Catarina: Epagri/UFSC, 2005.

PLEWKA, R.G.; ZAMULAK, J. R.; VENÂNCIO, J.A. et al. Avaliação do uso do pó de basalto na produção de feijão. Caderno Agroecologia, v.4, n.1, p.4397-4400, 2009.

SANTOS, R.H.S.; DA SILVA, F.; CASALI, V.W.D. et al. Efeito residual da adubação com composto orgânico sobre o crescimento e produção de alface. Pesquisa Agropecuária Brasileira, v.36, n.11, p.1395-1398, 2001.

SILVEROL, A.C.; MACHADO FILHO, L. Utilização de pó de granito e manto de alteração de piroxenito para fertilização de solos. Revista Brasileira de Agroecologia, v.2, n.1, 2007.

THEODORO, S.H.; LEONARDOS, O.; ROCHA E.L. et al. Experiências de uso de rochas silicáticas como fonte de nutrientes. Revista Espaço e Geografia, v.9, n.2, p.263-292, 2006.

Recebido para publicação em 10/02/2019 e aprovado em 19/06/2019. 